\title{
Pontibacter akesuensis sp. nov., isolated from a desert soil in China
}

\author{
Correspondence \\ Ren Lai \\ rlai72@njau.edu.cn \\ Wen-Jun Li \\ wjli@ynu.edu.cn
}

\author{
Yu Zhou, ${ }^{1} \dagger$ Xu Wang, ${ }^{1} \dagger$ Huan Liu, ${ }^{1}$ Ke-Yun Zhang, ${ }^{1}$ Yu-Qin Zhang, ${ }^{3,4}$ \\ Ren Lai ${ }^{1,2}$ and Wen-Jun Li ${ }^{3}$
}

${ }^{1}$ Key Laboratory of Microbiological Engineering of Agricultural Environment, Ministry of Agriculture, Life Sciences College of Nanjing Agricultural University, Nanjing, Jiangsu 210095 People's Republic of China

${ }^{2}$ Biotoxin Department of Key Laboratory of Animal Models and Human Disease Mechanisms, Kunming Institute of Zoology, Chinese Academy of Sciences, Kunming Yunnan 650223,

People's Republic of China

${ }^{3}$ Laboratory for Conservation and Utilization of Bio-Resources, Yunnan Institute of Microbiology and Yunnan University, Kunming, Yunnan 650091, People's Republic of China

${ }^{4}$ Institute of Medicinal Biotechnology, Chinese Academy of Medical Sciences \& Peking Union Medical College, Beijing 100050, People's Republic of China

\begin{abstract}
A Gram-negative, non-motile, rod-shaped bacterium, designated strain $\mathrm{AKS} 1^{\top}$, was isolated from a desert soil sample collected from Akesu, XinJiang Province, China. A taxonomic study, including phylogenetic analysis based on 16S rRNA gene sequences and phenotypic characteristics, was performed on the novel isolate. The predominant menaquinone of strain AKS $1^{\top}$ was MK-7. The major fatty acids included $\mathrm{i}-\mathrm{C}_{15: 0}$, ai- $\mathrm{C}_{17: 1} \mathrm{~B} / \mathrm{i}-\mathrm{C}_{17: 1}$ I and $\mathrm{i}-\mathrm{C}_{17: 0} 3-\mathrm{OH}$. The $\mathrm{G}+\mathrm{C}$ content of the DNA was $51.4 \mathrm{~mol} \%$. Based on the results of phenotypic and genotypic characteristics, strain AKS $1^{\top}$ should be assigned as representing a novel species of the genus Pontibacter, for which the name Pontibacter akesuensis is proposed. The type strain is AKS $1^{\top}\left(=\mathrm{KCTC} 12758^{\top}=\mathrm{CCTCC}\right.$ AB 206086 ${ }^{\top}$ ).
\end{abstract}

The genus Pontibacter belongs to the phylum Bacteroidetes and was first described by Nedashkovskaya et al. (2005b) based on a single isolate from an unidentified sea anemone. The main characteristics of members of the phylum Bacteroidetes include the ability to move by gliding (many lack motility), a rod-shaped or ring-shaped morphology, possession of Gram-negative cell walls and pigmentation. The majority of the members of the phylum Bacteroidetes have been isolated from seawater, sediment or algae. Some marine bacteria of the phylum Bacteroidetes possess menaquinone $7(\mathrm{MK}-7)$ as their main respiratory quinone (Bowman et al., 2003; Brettar et al., 2004a, b; Nedashkovskaya et al., 2003, 2004, 2005a, b; Raj \& Maloy, 1990; Van Trappen et al., 2004; Yi \& Chun, 2004; Yoon et al., $2004,2005 a, b, c)$. The present investigation was designed to establish the taxonomic position of a novel isolate that formed a common clade with the genus Pontibacter within the phylum Bacteroidetes. Although the novel isolate has some properties characteristic of the phylum Bacteroidetes, it also has many special properties that are distinct from other

†These authors contributed equally to this work.

The GenBank/EMBL/DDBJ accession number for the 16S rRNA gene sequence of strain AKS $1^{\top}$ is DQ672723. members of the phylum. Genotypic and phenotypic data show that the strain represents a novel species of the genus Pontibacter.

Strain AKS $1^{\mathrm{T}}$ was isolated from a desert soil sample collected from Akesu, XinJiang Province, north-west China, by using the traditional dilution plating method. LB agar (Sambrook \& Russell, 2002) was used for selective isolation and cultures were incubated at $30^{\circ} \mathrm{C}$ for 1 week. The novel strain was maintained on $\mathrm{LB}$ agar slants at $4{ }^{\circ} \mathrm{C}$ and as glycerol suspensions $(20 \%, \mathrm{v} / \mathrm{v})$ at $-80{ }^{\circ} \mathrm{C}$. Biomass for molecular systematic and chemotaxonomic studies was obtained after incubation in LB at $30{ }^{\circ} \mathrm{C}$ for 2 days in shake flasks (about 150 r.p.m.), with the $\mathrm{pH}$ adjusted to $\mathrm{pH} 7.8$ using $\mathrm{NaOH}$.

Cell morphology of the novel isolate was observed by light microscopy (BH2; Olympus) and by transmission electron microscopy (H-7650; Hitachi) after $24 \mathrm{~h}$ growth on LB medium. Acid production from carbohydrates was tested using the media and methods described by Gordon et al. (1974). Sole carbon and sole carbon/nitrogen source utilization was investigated using the Biolog GN2 Microplate system (Nedashkovskaya et al., 2005b) according to the manufacturers' instructions. Growth was tested at 4, 

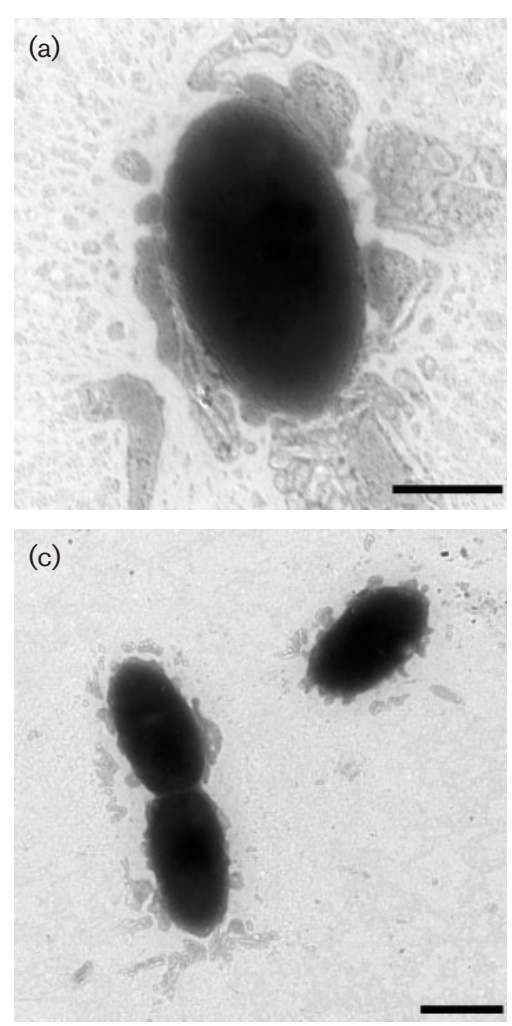
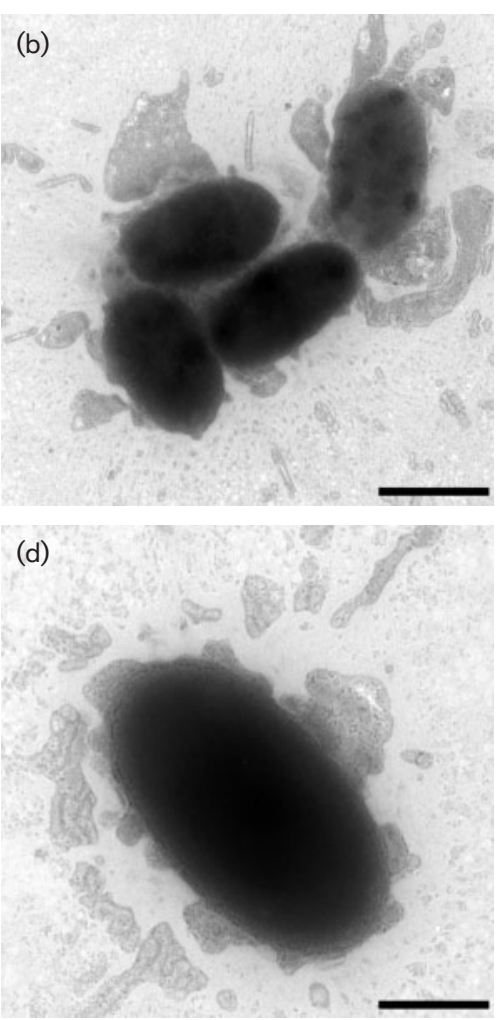

Fig. 1. Transmission electron micrographs of cells of strain AKS $1^{\top}$ grown on LB agar medium for $24 \mathrm{~h}$ at $30^{\circ} \mathrm{C}$. Bars, $500 \mathrm{~nm}(\mathrm{a}$, d) and $1 \mu \mathrm{m}(\mathrm{b}, \mathrm{c})$.
$10,27,30,36,37,40$ and $45^{\circ} \mathrm{C}$ on LB medium. Requirement for and tolerance of $\mathrm{NaCl}(1,4,7$, and $10 \%)$ and $\mathrm{pH}(3.0$, $6.0,7.0,7.8,8.0,10.0,11.0,12.0)$ were tested using modified LB medium. Susceptibility to antibiotics was examined as described by Nedashkovskaya et al. (2003, 2005b) with results recorded after incubation at $30{ }^{\circ} \mathrm{C}$ for up to 3 days. Gram-staining and other phenotypic characteristics were determined according to the method described by Gerhardt et al. (1994).
Menaquinones were extracted from lyophilized cells and determined using the procedures reported by AkagawaMatsushita et al. (1992) and $\mathrm{Hu}$ et al. (2001). Biomass for the quantitative fatty acid analysis was prepared by collecting growth from shake flasks of LB medium that had been incubated for 2 days at $30{ }^{\circ} \mathrm{C}$. Fatty acids were extracted, methylated and analysed using the standard MIDI (Microbial Identification) system as described by Sasser (1990).

Table 1. Phenotypic characteristics that differentiate strain AKS $1^{\top}$ from Pontibacter actiniarum KMM $6156^{\top}$

Both strains have a similar colony colour (pink) and give a positive result in tests for $\beta$-galactosidase activity. Both strains are able to hydrolyse aesculin and trypsin, but not Tweens 40 or 80 . +, Positive; -, negative. Data are from Nedashkovskaya et al. (2005b) and this study.

\begin{tabular}{|lcc|}
\hline Characteristic & Strain AKS $\mathbf{1}^{\mathbf{T}}$ & $\boldsymbol{P .}_{\text {actiniarum }} \mathbf{K M M ~} \mathbf{6 1 5 6}^{\mathbf{T}}$ \\
\hline Habitat & Soil & Marine \\
Cell size $(\mu \mathrm{m})$ & $0.7-0.75 \times 1.5-1.6$ & $0.3-0.4 \times 1.2-1.9$ \\
Gliding motility & - & + \\
$\alpha$-Galactosidase activity & + & - \\
Salinity range $(\%)$ & $0-4$ & $0-10$ \\
Temperature range $\left({ }^{\circ} \mathrm{C}\right)$ & $4-36$ & $6-43$ \\
Hydrolysis of: & & - \\
$\quad$ Agar & + & + \\
Starch & - & 48.7 \\
DNA G+C content $(\mathrm{mol} \%)$ & 51.4 & \\
\hline
\end{tabular}


Table 2. Cellular fatty acid content (\%) of strain AKS $1^{\top}$ and its closest relative, Pontibacter actiniarum KMM $6156^{\top}$

Summed fatty acids are those could not be separated by the Microbial Identification System. Data are from Nedashkovskaya et al. (2005b) and this study. Values are percentages of total fatty acids and values of $<1 \%$ are not shown.

\begin{tabular}{|c|c|c|}
\hline Fatty acid & AKS $1^{T}$ & KMM $6156^{\mathrm{T}}$ \\
\hline $\mathrm{i}-\mathrm{C}_{15: 1} \mathrm{~F}$ & 1.97 & - \\
\hline $\mathrm{i}-\mathrm{C}_{15: 1} \mathrm{I} / \mathrm{C}_{13: 0} 3-\mathrm{OH}$ & 1.72 & 2.3 \\
\hline $\mathrm{i}-\mathrm{C}_{15: 0}$ & 25.08 & 28.8 \\
\hline $\mathrm{C}_{15: 0}$ & 1.77 & - \\
\hline $\mathrm{i}-\mathrm{C}_{16: 0}$ & 1.46 & - \\
\hline $\begin{array}{l}\mathrm{i}-\mathrm{C}_{15: 0} 2-\mathrm{OH} / \mathrm{C}_{16: 1} \omega 7 \mathrm{cl} \\
\mathrm{C}_{16: 1} \omega 7 t\end{array}$ & 1.94 & 14.7 \\
\hline $\mathrm{C}_{16: 0}$ & 1.68 & 0.2 \\
\hline $\mathrm{i}-\mathrm{C}_{15: 0} 3-\mathrm{OH}$ & 3.33 & 3.0 \\
\hline $\mathrm{i}-\mathrm{C}_{17: 1} \omega 9 c$ & 7.69 & - \\
\hline ai- $\mathrm{C}_{17: 1} \mathrm{~B} / \mathrm{i}-\mathrm{C}_{17: 1} \mathrm{I}$ & 19.97 & 31.3 \\
\hline Unknown 16.582 & 1 & - \\
\hline ai- $\mathrm{C}_{18: 0} / \mathrm{C}_{18: 2} \omega 6,9 c$ & - & 1.8 \\
\hline $\mathrm{i}-\mathrm{C}_{17: 0}$ & 6.06 & 2.2 \\
\hline $\mathrm{C}_{17: 1} \omega 6 c$ & 2.87 & 1.4 \\
\hline $\mathrm{C}_{17: 0} / \mathrm{C}_{18: 0}$ & 2.41 & - \\
\hline $\mathrm{i}-\mathrm{C}_{18: 1} \mathrm{H} / \mathrm{C}_{18: 1} \omega 9 c l$ & 2.30 & - \\
\hline $\mathrm{C}_{18: 1} \omega 7 c / \mathrm{C}_{18: 1} \omega 5 c$ & & \\
\hline $\mathrm{i}-\mathrm{C}_{17: 0} 3-\mathrm{OH}$ & 11.46 & 6.5 \\
\hline
\end{tabular}

For the determination of $\mathrm{G}+\mathrm{C}$ composition, genomic $\mathrm{DNA}$ was prepared according to the method of Marmur (1961). The DNA G $+\mathrm{C}$ content of strain AKS $1^{\mathrm{T}}$ was determined using the thermal denaturation method (Mandel \& Marmur, 1968).

PCR amplification of the 16S rRNA gene was performed as described by $\mathrm{Xu}$ et al. (2003). Phylogenetic analysis was performed using the PHYLIP (Felsenstein, 1993) and MEGA version 3.1 (Kumar et al., 2001) software packages after multiple alignment of data by using CLUSTAL_X (Thompson et al., 1997). Distances (distance options according to the Kimura two-parameter model; Kimura, 1980, 1983) and clustering were based on the neighbour-joining (Saitou \& Nei, 1987) and maximum-likelihood (Felsenstein, 1981) methods. Bootstrap analysis was used to evaluate the tree topology of the neighbour-joining data by performing 1500 resamplings (Felsenstein, 1985).

Cells of strain AKS $1^{\mathrm{T}}$ were collected for morphological observations after being cultured on LB agar for $24 \mathrm{~h}$. Cells were prepared for transmission electron microscopy as described by Nedashkovskaya et al. (2005b). Cells of strain AKS $1^{\mathrm{T}}$ ranged from 0.7 to $0.75 \mu \mathrm{m}$ in width and from 1.5 to $1.6 \mu \mathrm{m}$ in length and an unknown ropy substance was observed around the cells (Fig. 1).

Colonies of strain AKS $1^{\mathrm{T}}$ were circular, convex, shiny, smooth and pink-coloured with diameters of 1-2 $\mathrm{mm}$ on LB agar for $48 \mathrm{~h}$. Colonies of strain AKS $1^{\mathrm{T}}$ were ropy and wet. Other physiological and biochemical characteristics are given in Table 1 and in the species description.

The predominant menaquinone was MK-7. The major fatty acids of strain AKS $1^{\mathrm{T}}$ were $\mathrm{i}-\mathrm{C}_{15: 0}$, ai- $\mathrm{C}_{17: 1} \mathrm{~B} / \mathrm{i}-\mathrm{C}_{17: 1}$ I and $\mathrm{i}-\mathrm{C}_{17: 0} 3-\mathrm{OH}$; detailed fatty acid profiles are shown in Table 2. The $\mathrm{G}+\mathrm{C}$ content of the DNA was $51.4 \mathrm{~mol} \%$.

The almost complete 16S rRNA gene sequence (1408 bp) of strain AKS $1^{\mathrm{T}}$ was determined and was used to construct a phylogenetic tree with reference sequences selected from the GenBank database following BLAST searches (unidentified and unpublished sequences were not considered). Phylogenetic analyses revealed that strain AKS $1^{\mathrm{T}}$ belongs to the phylum Bacteroidetes and is most closely related to the type strain of the only recognized species of the genus Pontibacter, Pontibacter actiniarum KMM $6156^{\mathrm{T}}$ (Fig. 2). The two strains formed a common group supported by a high bootstrap value (100\%).

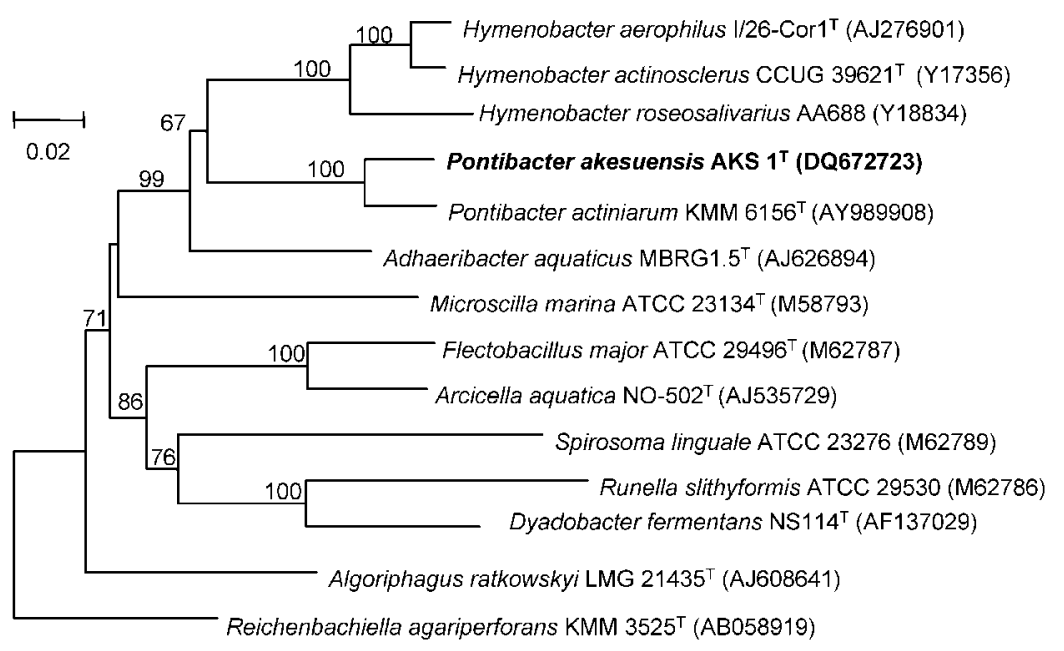

Fig. 2. Neighbour-joining phylogenetic tree based on the 16S rRNA gene sequences of strain AKS $1^{\top}$ and representative members of the phylum Bacteroidetes. Numbers at nodes indicate bootstrap values (\%). Bar, 0.02 substitutions per nucleotide position. 
Although P. actiniarum KMM $6156^{\mathrm{T}}$ and strain AKS $1^{\mathrm{T}}$ shared up to $95 \% 16 \mathrm{~S}$ rRNA gene sequence similarity and had similar menaquinone fingerprints (MK-7), they could be differentiated by their habitats and physiological and biochemical characteristics (Table 1). Strain AKS $1^{\mathrm{T}}$ was isolated from a desert soil, but $P$. actiniarum KMM $6156^{\mathrm{T}}$ was isolated from a marine habitat. Biolog GN2 tests indicated that about 70 different compounds could be utilized as sole carbon or sole carbon/nitrogen sources by strain AKS $1^{\mathrm{T}}$, while P. actiniarum KMM $6156^{\mathrm{T}}$ could only use 20 different compounds. Strain AKS $1^{\mathrm{T}}$ was resistant to kanamycin and sensitive to neomycin and gentamicin, but strain KMM $6156^{\mathrm{T}}$ was sensitive to kanamycin and resistant to neomycin and gentamicin. The features that differentiate strain AKS $1^{\mathrm{T}}$ from its nearest phylogenetic neighbour, $P$. actiniarum KMM $6156^{\mathrm{T}}$, are shown in Table 1.

In conclusion, genotypic, chemotaxonomic and phenotypic data demonstrate that strain AKS $1^{\mathrm{T}}$ represents a novel species of the genus Pontibacter, for which we propose the name Pontibacter akesuensis sp. nov.

\section{Description of Pontibacter akesuensis sp. nov.}

Pontibacter akesuensis (a.ke.su.en'sis. N.L. masc. adj. akesuensis pertaining to Akesu, a city of XinJiang Province in the north-west of China from where the type strain was isolated).

Cells range from 0.7 to $0.75 \mu \mathrm{m}$ in width and from 1.5 to $1.6 \mu \mathrm{m}$ in length. Colonies are circular, $1-2 \mathrm{~mm}$ in diameter, convex, shiny, pink and smooth on nutrient agar plates. Gram-negative. Cells are non-motile, nonspore-forming, aerobic and chemoorganotrophic. A ropy substance is observed around cells. Grows well in very dry environmental conditions, does not require $\mathrm{Na}^{+}$or other special substances for growth. Growth occurs at between 4 and $36{ }^{\circ} \mathrm{C}$, with an optimum at $28-30{ }^{\circ} \mathrm{C}$. Growth occurs at $\mathrm{pH} 7-11$, with optimal growth at $\mathrm{pH}$ 7.6-8.0. Growth occurs at $0-4 \% \mathrm{NaCl}$. Pigment can be extracted with organic solvents. Gelatin, DNA and starch are decomposed, but casein, Tweens 20, 40 and 80, cellulose and chitin are not hydrolysed. Forms acid from aesculin, D-fructose, Dsucrose, inositol, L-raffinose, D-maltose, $\mathrm{N}$-acetylglucosamine, L-fucose and D-glucose, but not from D-cellobiose, D-galactose, D-lactose, D-melibiose, L-rhamnose, L-sorbose or DL-xylose. In Biolog GN tests, the type strain utilizes $\alpha$ cyclodextrin, dextrin, glycogen, $N$-acetyl-D-galactosamine, Larabinose, D-arabitol, $N$-acetyl-D-glucosamine, D-cellobiose, $\mathrm{D}$-fructose, L-fucose, L-alanine, D-galactose, gentiobiose, $\alpha$ D-glucose, myo-inositol, maltose, D-mannitol, D-melibiose, methyl $\beta$-D-glucoside, D-psicose, D-raffinose, L-rhamnose, D-sorbitol, sucrose, D-trehalose, turanose, lactulose, xylitol, methyl pyruvate, monomethyl succinate, acetic acid, Dgalactonic acid lactone, cis-aconitic acid, D-galacturonic acid, D-gluconic acid, D-glucuronic acid, D-glucosaminic acid, $\alpha$-hydroxybutyric acid, $\beta$-hydroxybutyric acid, $\gamma$ hydroxybutyric acid, itaconic acid, $\alpha$-ketobutyric acid, $\alpha$ ketoglutaric acid, $\alpha$-ketovaleric acid, DL-lactic acid, propionic acid, quinic acid, D-saccharic acid, succinic acid, bromosuccinic acid, succinamic acid, L-alaninamide, L-alanyl glycine, L-asparagine, L-aspartic acid, L-glutamic acid, glycyl L-aspartic acid, glycyl L-glutamic acid, L-histidine, hydroxy-L-proline, L-leucine, L-ornithine, L-phenylalanine, L-proline, L-pyroglutamic acid, L-serine, L-threonine, DLcarnitine, $\gamma$-aminobutyric acid, inosine, thymidine, putrescine, 2,3-butanediol and glucose 6-phosphate. However, it does not utilize Tweens 20 , 40, or 80 , adonitol, i-erythritol, uridine, urocanic acid, $\alpha$-D-lactose, D-mannose, citric acid, formic acid, p-hydroxyphenylacetic acid, malonic acid, sebacic acid, glucuronamide, D-alanine, D-serine, phenylethylamine, 2 -aminoethanol, DL- $\alpha$-glycerol phosphate or glucose 1-phosphate. Nitrate is not reduced. Indole and $\mathrm{H}_{2} \mathrm{~S}$ (triple sugar iron reaction) are negative. Susceptible to the following antibiotics: ampicillin, benzylpenicillin, chloramphenicol, neomycin, gentamicin, erythromycin, carbenicillin, lincomycin and tetracycline. Resistant to kanamycin, polymyxin B and streptomycin. The predominant menaquinone is $\mathrm{MK}-7$. The fatty acid profile contains $\mathrm{i}-\mathrm{C}_{15: 0}$ (25.08\%), ai- $\mathrm{C}_{17: 1} \mathrm{~B} / \mathrm{i}-\mathrm{C}_{17: 1}$ I $(19.97 \%)$, i-C $\mathrm{C}_{17: 0} 3-\mathrm{OH}$ (11.46\%), i-C $\mathrm{C}_{17: 1} \omega 9 c(7.69 \%), \mathrm{i}-\mathrm{C}_{17: 0}(6.06 \%), \mathrm{i}-\mathrm{C}_{15: 0} 3-$ $\mathrm{OH}(3.33 \%), \mathrm{C}_{17: 1} \omega 6 c(2.87 \%), \mathrm{i}_{15: 1} \mathrm{~F}(1.97 \%), \mathrm{i}-\mathrm{C}_{15: 0}$ 2-OH/C $\mathrm{C}_{16: 1} \omega 7 c / \mathrm{C}_{16: 1} \omega 7 t(1.94 \%), \mathrm{C}_{15: 0}(1.77 \%), \mathrm{i}-\mathrm{C}_{15: 1}$ $\mathrm{I}^{-} \mathrm{C}_{13: 0} 3-\mathrm{OH}(1.72 \%), \mathrm{C}_{18: 0}(1.71 \%), \mathrm{C}_{16: 0}(1.68 \%)$, and $\mathrm{i}-\mathrm{C}_{16: 0}(1.46 \%)$. The DNA G $+\mathrm{C}$ content is $51.4 \mathrm{~mol} \%$.

The type strain, AKS $1^{\mathrm{T}}\left(=\mathrm{KCTC} 12758^{\mathrm{T}}=\right.$ CCTCC AB $206086^{\mathrm{T}}$ ), was isolated from the surface layer of a desert soil from Akesu, XinJiang Province, China.

\section{Acknowledgements}

This work was supported by grants from National Natural Science Foundation of China (Project no. 30600001), Jiangsu Natural Science Foundation (BK2005422) and Yunnan Science and Technology Commission (2005C0054M). W.-J.L. was also supported by the Program for New Century Excellent Talent in University (NCET).

\section{References}

Akagawa-Matsushita, M., Itoh, T., Katayama, Y., Kuraishi, H. \& Yamasato, K. (1992). Isoprenoid quinone composition of some marine Alteromonas, Marinomonas, Deleya, Pseudomonas and Shewanella species. J Gen Microbiol 138, 2275-2281.

Bowman, J. P., Nichols, C. M. \& Gibson, J. A. E. (2003). Algoriphagus ratkowskyi gen. nov., sp. nov., Brumimicrobium glaciale gen. nov., sp. nov., Cryomorpha ignava gen. nov., sp. nov. and Crocinitomix catalasitica gen. nov., sp. nov., novel flavobacteria isolated from various polar habitats. Int J Syst Evol Microbiol 53, 1343-1355.

Brettar, I., Christen, R. \& Höfle, M. G. (2004a). Belliella baltica gen. nov., sp. nov., a novel marine bacterium of the CytophagaFlavobacterium-Bacteroides group isolated from surface water of the central Baltic Sea. Int J Syst Evol Microbiol 54, 65-70.

Brettar, I., Christen, R. \& Höfle, M. G. (2004b). Aquiflexum balticum gen. nov., sp. nov., a novel marine bacterium of the CytophagaFlavobacterium-Bacteroides group isolated from surface water of the central Baltic Sea. Int J Syst Evol Microbiol 54, 2335-2341.

Felsenstein, J. (1981). Evolutionary trees from DNA sequences: a maximum likelihood approach. J Mol Evol 17, 368-376. 
Felsenstein, J. (1985). Conference limits on phylogenies: an approach using the bootstrap. Evolution 39, 783-791.

Felsenstein, J. (1993). PHYLIP (phylogeny inference package), version 3.5c. Department of Genome Sciences, University of Washington, Seattle, USA.

Gerhardt, P., Murray, R. G. E., Wood, W. A. \& Krieg, N. R. (editors) (1994). Methods for General and Molecular Bacteriology. Washington, DC: American Society for Microbiology.

Gordon, R. E., Barnett, D. A., Handerhan, J. E. \& Pang, C. H. N. (1974). Nocardia coeliaca, Nocardia autotrophica, and the nocardin strain. Int J Syst Bacteriol 24, 54-63.

Hu, H. Y., Lim, B. R., Goto, N. \& Fujie, K. (2001). Analytical precision and repeatability of respiratory quinones for quantitative study of microbial community structure in environmental samples. J Microbiol Methods 47, 17-24.

Kimura, M. (1980). A simple method for estimating evolutionary rates of base substitutions through comparative studies of nucleotide sequence. J Mol Evol 16, 111-120.

Kimura, M. (1983). The Neutral Theory of Molecular Evolution. Cambridge: Cambridge University Press.

Kumar, S., Tamura, K., Jakobsen, I. B. \& Nei, M. (2001). MEGA2: molecular evolutionary genetics analysis software. Bioinformatics 17, 1244-1245.

Mandel, M. \& Marmur, J. (1968). Use of ultraviolet absorbancetemperature profile for determining the guanine plus cytosine content of DNA. Methods Enzymol 12B, 195-206.

Marmur, J. (1961). A procedure for the isolation of deoxyribonucleic acid from microorganisms. J Mol Biol 3, 208-218.

Nedashkovskaya, O. I., Suzuki, M., Vysotskii, M. V. \& Mikhailov, V. V. (2003). Reichenbachia agariperforans gen. nov., sp. nov., a novel marine bacterium in the phylum Cytophaga-FlavobacteriumBacteroides. Int J Syst Evol Microbiol 53, 81-85.

Nedashkovskaya, O. I., Vancanneyt, M., Van Trappen, S., Vandemeulebroecke, K., Lysenko, A. M., Rohde, M., Falsen, E., Frolova, G. M., Mikhailov, V. V. \& Swings, J. (2004). Description of Algoriphagus aquimarinus sp. nov., Algoriphagus chordae sp. nov. and Algoriphagus winogradskyi sp. nov., from sea water and algae, transfer of Hongiella halophila Yi and Chun 2004 to the genus Algoriphagus as Algoriphagus halophilus comb. nov. and emended descriptions of the genera Algoriphagus Bowman et al. 2003 and Hongiella Yi and Chun 2004. Int J Syst Evol Microbiol 54, 1757-1764.

Nedashkovskaya, O. I., Kim, S. B., Lee, D. H., Lysenko, A. M., Shevchenko, L. S., Frolova, G. M., Mikhailov, V. V., Lee, K. H. \& Bae, K. S. (2005a). Roseivirga ehrenbergii gen. nov., sp. nov., a novel marine bacterium of the phylum 'Bacteroidetes', isolated from the green alga Ulva fenestrata. Int J Syst Evol Microbiol 55, 231-234.
Nedashkovskaya, O. I., Kim, S. B., Suzuki, M., Shevchenko, L. S., Lee, M. S., Lee, K. H., Park, M. S., Frolova, G. M., Oh, H. W. \& other authors (2005b). Pontibacter actiniarum gen. nov., sp. nov., a novel member of the phylum 'Bacteroidetes', and proposal of Reichenbachiella gen. nov. as a replacement for the illegitimate prokaryotic generic name Reichenbachia Nedashkovskaya et al. (2003). Int J Syst Evol Microbiol 55, 2583-2588.

Raj, H. D. \& Maloy, S. R. (1990). Proposal of Cyclobacterium marinus gen. nov., comb. nov. for a marine bacterium previously assigned to the genus Flectobacillus. Int J Syst Bacteriol 40, 337-347.

Saitou, N. \& Nei, M. (1987). The neighbor-joining method: a new method for reconstructing phylogenetic trees. Mol Biol Evol 4, $406-425$.

Sambrook, J. \& Russell, D. W. (2002). Molecular Cloning: a Laboratory Manual, pp. 1595-1596, 3rd edn. Cold Spring Harbor, NY: Cold Spring Harbor Laboratory.

Sasser, M. (1990). Identification of bacteria by gas chromatography of cellular fatty acids. USFCC Newsl 20, 1-6.

Thompson, J. D., Gibson, T. J., Plewniak, F., Jeanmougin, F. \& Higgins, D. G. (1997). The CLUSTAL_X windows interface: flexible strategies for multiple sequence alignment aided by quality analysis tools. Nucleic Acids Res 24, 4876-4882.

Van Trappen, S., Vandecandelaere, I., Mergaert, J. \& Swings, J. (2004). Algoriphagus antarcticus sp. nov., a novel psychrophile from microbial mats in Antarctic lakes. Int J Syst Evol Microbiol 54, 1969-1973.

Xu, P., Li, W. J., Xu, L. H. \& Jiang, C. L. (2003). A microwave-based method for genomic DNA extraction from Actinomycetes. Microbiology (Beijing) 30, 82-84 (in Chinese).

Yi, H. \& Chun, J. (2004). Hongiella mannitolivorans gen. nov., sp. nov., Hongiella halophila sp. nov. and Hongiella ornithinivorans sp. nov., isolated from tidal flat sediment. Int J Syst Evol Microbiol 54, 157-162.

Yoon, J.-H., Yeo, S.-H. \& Oh, T.-K. (2004). Hongiella marincola sp. nov., isolated from sea water of the East Sea in Korea. Int J Syst Evol Microbiol 54, 1845-1848.

Yoon, J.-H., Kang, S.-J., Lee, C.-H. \& Oh, T.-K. (2005a). Marinicola seohaensis gen. nov., sp. nov., isolated from sea water of the Yellow Sea, Korea. Int J Syst Evol Microbiol 55, 859-863.

Yoon, J.-H., Kang, S.-J., Jung, S.-Y., Lee, C.-H. \& Oh, T.-K. (2005b). Algoriphagus yeomjeoni sp. nov., isolated from a marine solar saltern in the Yellow Sea, Korea. Int J Syst Evol Microbiol 55, 865-870.

Yoon, J.-H., Kang, S.-J. \& Oh, T.-K. (2005c). Algoriphagus locisalis sp. nov., isolated from a marine solar saltern. Int J Syst Evol Microbiol 55, 1635-1639. 